Disseminated intravascular coagulation (DIC) is an important feature of pre-eclampsia and eclampsia, but its correction with a low-dose heparin regimen has not been reported to reduce the incidence of hypertension, proteinuria, or oedema. ${ }^{12}$ Since, however, convulsions may be a manifestation of rapid DIC, ${ }^{13}$ heparin treatment in severe pre-eclampsia may prevent their onset; but in eclampsia cerebral haemorrhage is a serious hazard and anticoagulant therapy would be highly dangerous.

Despite the reduction in the maternal mortality rate, the perinatal mortality rate remains about $15 \%$, usually as a result of prematurity. Future progress will depend on the more efficient detection and treatment of pre-eclampsia, so enabling pregnancy to remain uninterrupted for longer, even in severe cases.

1 Department of Health and Social Security, Report on Confidential Enquiries into Maternal Deaths in England and Wales, 1970-1972. London, HMSO, 1975.

2 Dewar, J B, and Morris, W I C, Fournal of Obstetrics and Gynaecology of the British Empire, 1947, 54, 417.

${ }^{3}$ Menon, M K K, Fournal of Obstetrics and Gynaecology of the British Empire, 1956, 63, 847.

${ }^{4}$ Lean, T H, Ratnam, S S, and Sivasamboo, R, Fournal of Obstetrics and Gynaecology of the British Commonwealth, 1968, 75, 856.

5 Duffus, G M, Tunstall, M E, and MacGillivray, I, Lancet, 1968, 1, 335.

6 Pritchard, J A, and Pritchard, S A, American fournal of Obstetrics and Gynaecology, 1975, 123, 543.

7 Tulzer, W, Wiener klinische Wochenschrift, 1970, 82, 304.

${ }^{8}$ Cree, J E, Meyer, J, and Hailey, D M, British Medical fournal, 1973, 4, 251.

${ }^{9}$ Scher, J, Hailey, D M, and Beard, R W, Fournal of Obstetrics and Gynaecology of the British Commonwealth, 1972, 79, 635.

10 Schiff, D, Chan, G, and Stern, L, Pediatrics, 1971, 48, 139.

11 Johnson, R A, British Medical fournal, 1976, 1, 943.

12 Bonnar, J, in Clinics in Obstetrics and Gynaecology, ed F E Hytten, vol 2, p 321. London, Saunders, 1975.

13 Page, E W, Villee, C A, and Villee, D B, in Human Reproduction, p 382. Philadelphia, Saunders, 1972.

\section{Why do we let dogs foul our streets?}

The public is now becoming more aware of the problems caused by domestic pets in Britain, and much of this has come from the effect of articles published in the $B M \mathcal{F} .{ }^{12}$ In the United States this awareness and concern are considerably greater than in Britain, and when the National League of Cities in America carried out a survey of the country's mayors and asked "What do citizens most frequently complain about ?" over $60 \%$ of the answers put in first rank "dogs and animal control problems."'3

In Britain there are at least 5 million dogs, yet only about $2 \frac{1}{2}$ million are licensed. There are probably about the same number of cats, but-because these are more local in their habits, rarely range in public parks, and on average are considerably smaller than dogs-cats create less of a problem, particularly so far as contamination of public streets and parks are concerned.

What are the health problems created by dogs? In Britain, undoubtedly the most common is toxocariasis, though dogs transmit other helminths, particularly Echinococcus granulosus causing hydatid disease, and in tropical countries Ancylostoma caninum, Strongyloides stercoralis, Trichuris vulpis, and Uncinaria stenocephela. Dogs also play a part in the transmis- sion of Multiceps infections and occasionally form a subsidiary link in the chain of transmission of toxoplasmosis. Among bacterial diseases they have occasionally been implicated in Salmonella infections, and among virus diseases they are the main agent of transmission of rabies to man. Perhaps the principal reason why dogs aroused little concern over health in the past is that, of the helminthic infections which they transmit, hydatid disease was the best known, yet it was rarely transmitted in Britain. Moreover, of human toxocariasis virtually nothing was known until about 12 years ago. Rabies has not yet spread to animals in Britain, but the recent occurrence in London of two human cases contracted overseas a year ago and the known spread of the disease among animals to within 40 miles of Paris have been causing increasing concern. Sources of illegal importation of animals into the country should be sought out and stopped. Possible sources such as people travelling from the Continent by car, small boats, and light aircraft, as well as by helicopters from North Sea oil rigs should all be examined; arrangements for inspection augmented; and punishment for evaders made fitting to the seriousness to the community.

The danger already in our midst is, however, the more important. Toxocariasis is already causing damage to sight, and the known cases represent only the tip of the iceberg. As many as $6 \%$ of apparently healthy persons have evidence of past infection with toxocariasis ${ }^{2}{ }^{4}$ and a substantial proportion of infected persons develop respiratory and other complications of the infection. The degree of contamination of the environment with toxocaral ova was shown by Borg and Woodruff ${ }^{1}$ in 1973, when they found that only some of those with toxocariasis had had close contact with a dog. From this they deduced that these patients might have been infected with ova transmitted through contaminated soil in public places frequented by dogs. Examination of the soil in parks in Britain showed that $24 \%$ of specimens were contaminated-a remarkably high degree. Clearly we need much more control of pollution of public places by dogs and cats.

A point which favours increased prevalence of toxocariasis is the now lower average age of our dogs. Many thousands of abandoned dogs are destroyed each year and further thousands are killed on the roads. In America something like $12 \%$ of dogs are killed every year..$^{5}$ Any lowering of the average age of dogs means that they are more susceptible to toxocaral infection than otherwise, for as dogs grow older their immunity to the infection increases. A further disturbing trend is the move for larger dogs to become popular. This has certainly occurred in the United States of America, possibly as a defence against urban crime. In the USA the registration of the larger breeds showed considerable increases between 1963 and 1972; the numbers of St Bernards registered increased elevenfold, of Great Danes sixfold, and of Doberman Pinschers 6.6-fold. Larger dogs cause more environmental contamination than smaller breeds, and their greater prevalence is a factor in the growth of public anxiety about the health hazards of dog excreta.

Developed communities have long been conscious of the need for high standards of hygiene for human excreta. Given what we now know about toxocariasis, should we not demand the same for dogs?

\footnotetext{
${ }^{1}$ Borg, O A, and Woodruff, A W, British Medical fournal, 1973, 4, 470.

2 Woodruff, A W, British Medical fournal, 1970, 3, 663.

3 Beck, A M, American Fournal of Public Health, 1975, 65, 1315.

4 Woodruff, A W, Transactions of the Royal Society of Tropical Medicine and Hygiene, 1973, 67, 755.

5 Beck, A M, Nations Cities, 1974, 12, 28.
} 